\title{
Detection of Canine Parvovirus in Baghdad city by PCR technique
}

\author{
Ahmed F. Ahmed ${ }^{1}$,Shony M. Odeisho ${ }^{1}$,Zhala A. Karim ${ }^{2}$ \\ 1-Department of Microbiology, College of Veterinary Medicine- Baghdad University,Iraq.2- \\ Sulaimaniyah University, Ministry of high education
}

\begin{abstract}
Summary
Canine parvovirus 2 (CPV2) is a highly contagious and fatal disease of dogs, causing acute hemorrhagic enteritis and myocarditis. In this study different mutant strains of the virus were characterized by polymerase chain reaction (PCR).The fecal samples from infected dogs suspected for CPV2 infection were collected in a suitable medium. The viral DNA from fecal samples was extracted using specific kits, PCR were carried out with five different primer, pCPV-2ab and pCPV-2b, to distinguish the strain prevalent in field condition. The primer pCPV-2ab recognized both variant CPV-2a and CPV-2b, whereas the primer pCPV-2b recognized only the variant $\mathrm{CPV}-2 \mathrm{~b}$, using the third primer $\mathrm{pCPV}$ to recognize the residual base pair, enabling the differentiation of CPV-2a variant from CPV-2b in field isolates. The different PCR products were further analyzed by using gel electrophoresis.

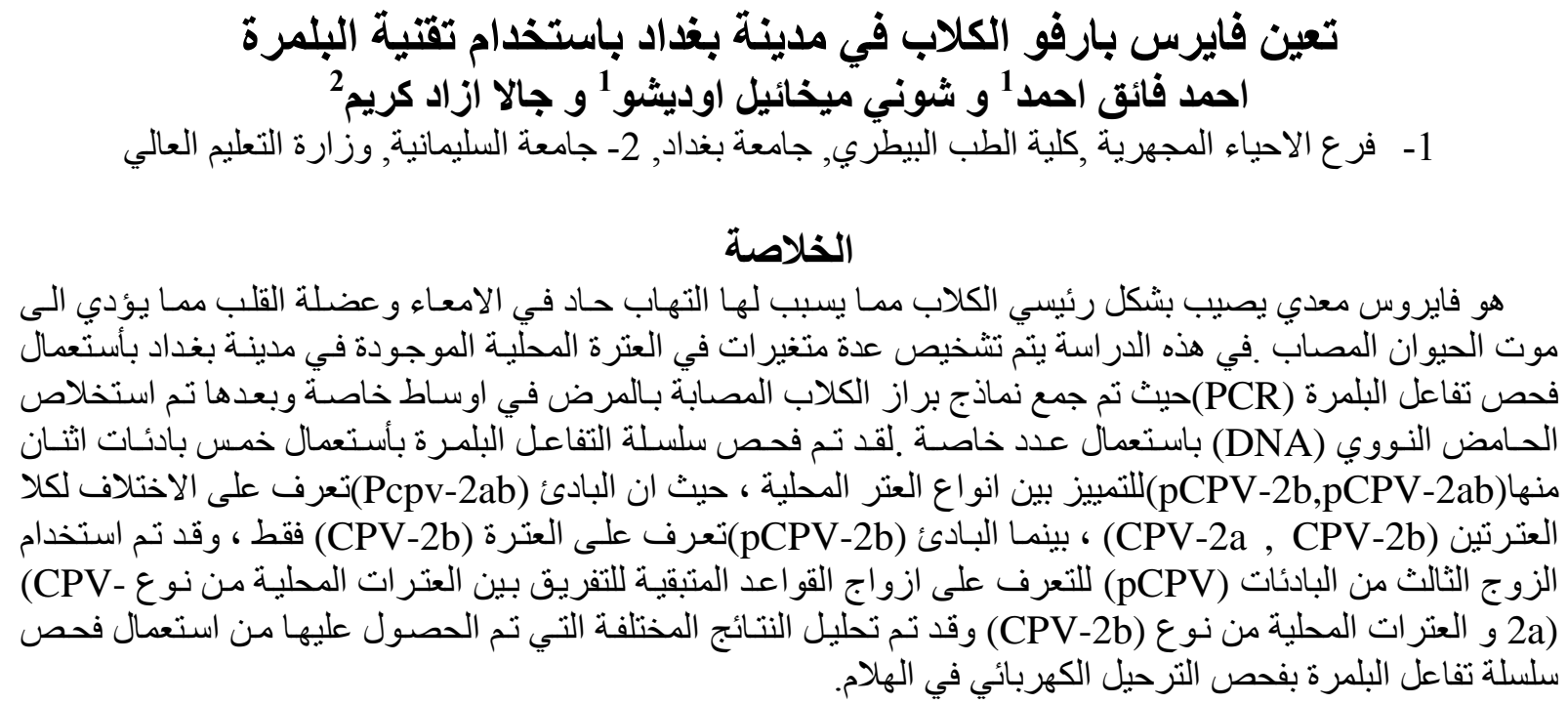

\section{Introduction}

Canine parvovirus 2 (CPV-2) causes a highly contagious and often fatal disease, characterized by vomiting and hemorrhagic gastroenteritis in dogs of all age (1), and myocarditis and subsequent heart failure in pups of less than 3 month of age. CPV-2 emerged in 1978 as the cause of new disease in dogs throughout the world, when it rapidly spread in domestic dog populations as well as wild dogs with high morbidity (100\%) and frequent mortality up to $10 \%(1,2)$.

The main source of infection is the feces of infected dogs containing large numbers of virus particles $\left(10^{9}\right.$ virus particles/g of faeces) that excreted in the faeces. Between 1979 and 1981 the original (1978) strain of the virus (CPV-2) had been replaced by a genetically and antigenically variant strain termed CPV-2a (3). The two viruses differ in 5-6 amino acids, which constitute two different neutralizing antigenic sites on the surface of the capsid. In 1984, a further antigenically variant virus was detected which differ in only a single epitope, designated as CPV-2b (4).The CPV-2, a non-enveloped virus with an approximate diameter of $20 \mathrm{~nm}$, is a member of the genus Parvovirus of the family Parvoviridae.This virus was detected and isolated in Iraq at 2009(5). 
In the present, $\mathrm{CPV}-2$ present in Iraq has been characterized and strain differentiated by using polymerase chain reaction (PCR).

\section{Materials and Methods}

The faecal samples were collected from 12 dogs came to Veterinary hospital (Baghdad, Adan square) between March-June/ 2011 that showing the symptoms of fever, diarrhoea or hemorrhagic diarrhoea and vomition, clinically suspected for CPV infections. The faecal samples were collected by rectal disposable swab, and directly transferred in ice to the laboratory of Kurdistan institute for strategic studies and scientific researches (Sulaymaniyah city), stored at $\left(-20^{\circ} \mathrm{C}\right)$ until the DNA was extracted. A commercially available inactivated vaccine was used as a positive control of CPV and a stool sample from a healthy dog processed similarly was used as a negative control.The viral DNA was extracted from fecal sample using InnuPREP Stool DNA Kit (aj ROBOSCREENInc, Germany) according to the manufacturer's protocol.

The PCR was standardized for the primer set pCPV-2ab and pCPV-2b, as designed under the scientific standards in primer designing with slight modifications (6). The details of primers are given in Table 1.

The PCR reaction mixture contained $100 \mu \mathrm{M}$ dNTPs, 10 pmol of each primer, $1 \times$ PCR reaction mixture containing $12.5 \mathrm{mM} \mathrm{MgCl}^{2}$ and $5 \mu \mathrm{L}$ of processed sample as source of template DNA. Amplification was performed in a thermocycler (AppliedBiosystems, Veriti $\left.^{T M}\right) .1 \mu \mathrm{L}$ of DNA polymerase $(1 \mathrm{IU} / \mu \mathrm{L})$ was added to above reaction mixture after initial denaturation was done at $95^{\circ} \mathrm{C}$ for $5 \mathrm{~min}$ in the thermocycler. The cyclic condition was denaturation at $95^{\circ} \mathrm{C}$ for $4 \mathrm{~min}$, primer annealing at $50^{\circ} \mathrm{C}$ for $1 \mathrm{~min}$ and extension at $72^{\circ} \mathrm{C}$ for $1 \mathrm{~min}$. The cyclic condition was repeated for 35 times and a final extension at $72^{\circ} \mathrm{C}$ was given for $10 \mathrm{~min}$ (5). After PCR, the amplified products were analyzed on $1.0 \%$ agarose gel containing ethidium bromide to a final concentration of $0.5 \mu \mathrm{g} / \mathrm{mL} .10 \mu \mathrm{L}$ of amplified product was loaded into the well and run along with $100 \mathrm{bp}$ to $1 \mathrm{Kbp}$ DNA ladder in $1 \times \mathrm{TBE}$ electrophoresis buffer at 5 volts $/ \mathrm{cm}^{2}$ and the progress of mobility was monitored by migration of dye. At the end of the electrophoresis, the gel was visualized under the UV transilluminator.

Table 1- Details of primer sets used

\begin{tabular}{|c|c|c|c|c|}
\hline No. & $\begin{array}{l}\text { Forward and } \\
\text { reverse primers }\end{array}$ & Primer sequence & $\begin{array}{c}\text { Position of } \\
\text { Primer on } \\
\text { genome }\end{array}$ & $\begin{array}{c}\text { Annealing } \\
\text { temperature } \\
\text { and product size }\end{array}$ \\
\hline 1 & $\mathrm{pCPV}-2 \mathrm{ab}(\mathrm{F})$ & AGTGATGGAGCAGTTCAACCAGACG & \multirow{2}{*}{$\begin{array}{c}2790-2814 \text { to } \\
3448-3371\end{array}$} & \multirow{2}{*}{$\begin{array}{c}50^{\circ} \mathrm{C} \\
658 \mathrm{bp}\end{array}$} \\
\hline 2 & pCPV-2ab (R) & GTGTGCCACTAGTTCCAGTATGAG & & \\
\hline 3 & pCPV-2b (F) & CCATCTCATACTGGAACTAGTGGCAC & \multirow{2}{*}{$\begin{array}{c}3444-3469 \text { to } \\
4335-4317\end{array}$} & \multirow{2}{*}{$\begin{array}{c}50^{\circ} \mathrm{C} \\
891 \mathrm{bp}\end{array}$} \\
\hline 4 & pCPV-2b (R) & TAGCAGATGCATCAGGATC & & \\
\hline 5 & pCPV-(F) & CCATCTCATACTGGAACTAGTGGCAC & \multirow{2}{*}{$\begin{array}{c}3444-3469 \text { to } \\
4426-4405\end{array}$} & \multirow{2}{*}{$\begin{array}{c}50^{\circ} \mathrm{C} \\
982 \mathrm{bp}\end{array}$} \\
\hline 6 & pCPV-(R) & GGATTCCAAGTATGAGAGGCTC & & \\
\hline
\end{tabular}

\section{Results}

In the present study, PCR was carried out on 9 stool samples collected from CPV suspected dogs and used as template to amplify the VP2 structural gene of CPV genome. Of the 9 stool samples from the suspected cases of CPV infections, 6 were found to be positive by pCPV-2b primer set, whereas all of them are amplified by pCPV-2ab primer set $(7,8)$. The pCPV-2ab primer set amplified portion of VP2 gene of both CPV-2a and CPV-2b variants (2790 to 3448 nucleotide position of CPV genomic DNA) to yield a product size of 658 bp (Fig.1). 


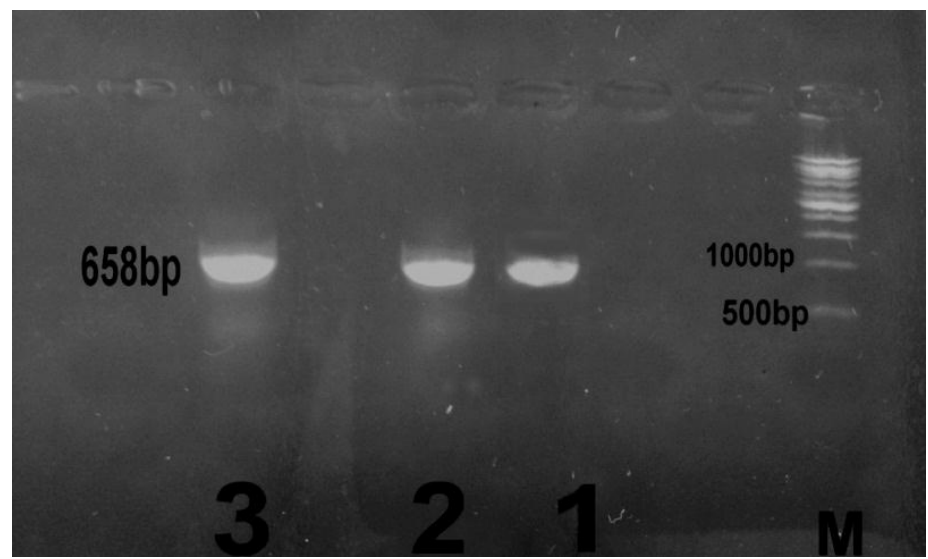

Fig. 1-Showing amplicon of 658 bp of CPV-2a or CPV-2b positive samples using pCPV-2ab (F and R) primers: Lane M, DNA marker 5 kbp; lane 1, 681 bp PCR product of sample no. 1, lane 2, 681 bp PCR product of sample no. 2; lane 3, 681 bp PCR product of positive control (puppy vaccine).

The pCPV-2b primer pair amplified specific portion VP2 gene of only CPV-2b (3444 to 4335 nucleotide position of CPV genomic DNA) to yield a product size of $891 \mathrm{bp}$ and thereby differentiate between CPV-2a and CPV-2b (9) (Fig. 2). So the results showed that out of 9 samples 6 were of CPV-2b variant, while 3 were CPV-2a strain. Then the third pairs of primers pCPV (FandR) residual part of gene from (3444 to 4426 nucleotide position of CPV genomic DNA) yield a product size of $891 \mathrm{bp}$, seen the specificity with all samples to give positive result.

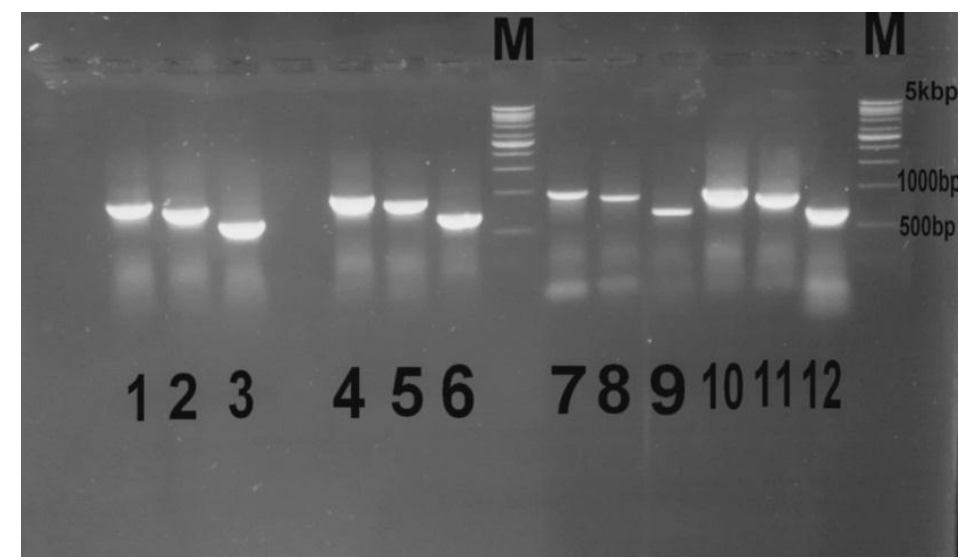

Fig. 2-Showing amplicon of 12 sample as; lane 3,6,9,12 658bp of CPV-2a or CPV-2b and; lane 2,5,8,11 891bp positive samples using CPV-2b (FandR) primers: Lane 1,4,7,10 982bp positive result using CPV (FandR) primers; Lane M, DNA marker 5 kbp.

\section{Discussion}

Canine parvovirus infections have been emerged as the most important killer disease of pups in recent time as it causes vomiting, myocarditis and hemorrhagic gastroenteritis (9). Although adult dogs show less severe symptoms of gastroenteritis, the dogs serve as a source of infection. Due to its immunosuppressive nature, CPV decreases the animal's ability to fight against infections (10). After emergence of the CPV-2, two more mutants, namely CPV-2a and CPV-2b, have been reported and completely replaced the original strain (CPV2) around the world (4). Decaro(11) identified different variants of CPV circulating in dog population in Spain. Truyen(12) studied that CPV-2a and CPV-2b have almost completely replaced the original CPV2 in canine population in Germany. Pereira(8) reported that the predominant strain found in Brazil during 1980 was CPV-2a and CPV-2b during 1990-1995. Wang (13) reported both antigenic types CPV-2a and CPV-2b prevailing in Taiwan. Battilani(14) showed that both antigenic types $2 \mathrm{a}$ and $2 \mathrm{~b}$ co-exist in canines in Italy. This study is the first one carried out in Iraq, Thus, PCR technique can be adopted to diagnose rapidly, reproducibly 


\section{Proceeding of the Eleventh Veterinary Scientific Conference, 2012; 95-98}

and accurately the CPV infections. Further, different antigenic variants of CPV can also be differentiated by employing PCR with different combination of primer sets.

From the present study, it is inferred that CPV-2b is more prevalent in dog population in Baghdad city as revealed in PCR based diagnosis. So, necessary measures should be taken to control the disease in dogs by incorporating the indigenous strain of CPV in the preparation of vaccine.

\section{References}

1. Appel,MJ .; Scott, FW.and Carmichael, LE. (1979).Isolation and immunization studies of a canine parvo-like virus from dogs with hemorrhagic enteritis, Vet. Res., 105: 156-159.

2. Kelly, WR.and Atwell R B, (1979). Diffuse subacute myocarditis of possible viral etiology: A cause of sudden death in pups. Aust. Vet. J., 55: 36-37.

3. Parrish, C. R.; O'Connell, P. H.;Evermann, J. F.andCarrmichael, L. E.(1985).Natural variation of canine parvovirus. Science, 230: 1046-1048.

4. Parrish, C. R.;Aquadro, C. F.and Carmichael, L. E.(1988).Canine host range and a specific epitope map along with variant sequences in the capsid protein gene of canine parvovirus and related feline mink and racoon parvoviruses. Virology, 166: 293-307.

5. Ali, M. H.(2009). Detection and isolation of Canine Parvovirus in Iraq, MSc. thesis Baghdad, University of Baghdad.

6. Sambrook, J.and Russell, D. W.(2001). Molecular cloning: A laboratory manual. $3^{\text {rd }}$ ed. Cold Spring Harbor laboratory Press, New York.

7. Nandi, S.;Pandey, A. B.; Sharma, K.andChauhan, R. S. (2008). Polymerase chain reaction for the detection of canine parvoviral DNA in vaccines. Indian J.Virol, 19: 9-11.

8. Schunck, B.; Kraft, W.andTruyen, U. A. (1995). Simple touch-down polymerase chain reaction for the detection of canine parvovirus and feline panleukopenia virus in feces. J.Virol.Methods, 55: 427-33.

9. Pereira, C. A.;Monezi, T. A.; Mehnert, D. U.;D’Angelo, M.andDurigon, E. L. (2000). Molecular characterization of canine parvovirus in Brazil by PCR. Vet.Microbiol., 75:127133.

10. Legendre, A. M.(2000). Parvovirus in dog in Text book of veterinary internal medicine. Diseases of the dog and cat. ${ }^{\text {th }}$ ed. S J Ettingerand E C Feldman (W B Saunders Co., Philadelphia, USA.,pp: 1958.

11. Decaro, N.;Martella, V.;Desario, C.;Bellaciccio, A. L.;Camero, M.(2006). First detection of canine parvovirus type 2c in pups with haemorrhagic enteritis in Spain. J. Vet. Med., 53: 468472.

12. Truyen, U.;Platzer, G.and Parrish, C. R.(1996). Antigenic type distribution among canine parvoviruses in dogs and cats in Germany. Vet. Rec., 138: 365-366.

13. Wang, H. C.; Chen, W.D.;Lin, S. L.; Chan, J. P.and Wong, M. L. (2005). Phylogenetic analysis of canine parvovirus VP2 gene in Taiwan. Virus Gene., 31: 171-174.

14. Battilani, M.;Scagliarini, A.;Tisato, E.;Turilli, C.andJacoboni, I.(2001). Analysis of canine parvovirus sequences from wolves and dogs isolated in Italy. J. Gen.Virol., 82: 1555-1560. 